\title{
Elective Surgical Procedure
}

National Cancer Institute

\section{Source}

National Cancer Institute. Elective Surgical Procedure. NCI Thesaurus. Code C51996.

Surgery that may be scheduled or undertaken by choice. 